\title{
Effects of zeolites $X$ and $Y$ on the degradation of malathion in water
}

\author{
Joanne Atieno Ogunah ${ }^{1}$, Chrispin Ounga Kowenje ${ }^{*, 1}$, Elly Tetty Osewe ${ }^{2}$, Joseph Owour Lalah ${ }^{3}$, \\ David Agoro Jaoko ${ }^{1}$, Robert Njuguna Koigi ${ }^{4}$
}

${ }^{1}$ Department of Chemistry, Maseno University, P. O. Box 333-40105, Maseno, Kenya

${ }^{2}$ Kisumu Polytechnic P. O. Box 143-40100, Kisumu, Kenya

${ }^{3}$ Department of Chemical Sciences and Technology, Technical University of Kenya, P. O. Box 52428-00200, Nairobi, Kenya

${ }^{4}$ Kenya Plant Health Inspectorate Service, P. O. Box 49592-00100 Nairobi, Kenya

Email address:

kowenje@yahoo.com / ckowenje@maseno.ac.ke (C. Ounga Kowenje)

\section{To cite this article:}

Joanne Atieno Ogunah, Chrispin Ounga Kowenje, Elly Tetty Osewe, Joseph Owour Lalah, David Agoro Jaoko, Robert Njuguna Koigi. Effects of Zeolites X and Y on the Degradation of Malathion in Water. Science Journal of Chemistry. Vol. 1, No. 1, 2013 , pp. 7-13.

doi: $10.11648 /$ j.sjc. 20130101.12

\begin{abstract}
The inclusion of both zeolites X and zeolite $\mathrm{Y}$ significantly affected the dissipation of malathion in water. In the fresh water, malathion degradation followed a pseudo-first order kinetics with concomitant half-life dropping from 8.76 hours in fresh water to 4.44 and 6.65 hours up on the introduction of faujasite X and Y, respectively. Zeolite X had higher degradation efficiency as compared to the $\mathrm{Y}$ type. In pure fresh water, Malathion mainly hydrolyzed to form malathion monocarboxylic and dicarboxylic acids as the only degradation products. However, in the presence of zeolites X and Y, in addition to the degradation products obtained in the fresh water, dimethyldithiophosphate was also formed. Notably, all the degradation products obtained are environmentally benign compared to the parent malathion. Eventually, both the adsorption on the zeolite framework and zeolite catalyzed degradation processes contributed to the overall dissipation behavior of the malathion and its degradation products.
\end{abstract}

Keywords: Degradation Kinetics, Faujasite X And Y, Fresh Water, Half Life, Malathion

\section{Introduction}

Malathion (S- 1, 2- bis (ethoxycarbony 1) ethyl $O$, $O$ dimethylphosphorodithioate $\left.-\mathrm{C}_{10} \mathrm{H}_{19} \mathrm{O}_{6} \mathrm{PS}_{2}\right)$ belongs to the organophosphate class of pesticides [1]. Human exposure to malathion may result in nausea, vomiting, stomach cramps, diarrhea, blurred vision, confusion, sweating, muscle twitching, irregular heartbeat and eventually convulsions and fatality [1]. Malathion usually adsorbs on soils and through surface runoff and leaching, it finds its way into rivers and lakes whose waters, in most cases, the surrounding population rely on for their domestic use [2]. Malathion degradation in water is $\mathrm{pH}$ dependent, with faster decomposition at higher $\mathrm{pH}$ [3]. Hydrolysis is the main route of decomposition in alkaline aerobic conditions though biodegradation may also play a role [4]. Metabolites resulting from hydrolysis include malaoxon, malathion alpha and beta monoacid, diethyl fumarate, diethyl thiomalate, $O, O$ - dimethylphosphorodithioic acid, diethylthiomalate, and $O, O$ dimethylphosphorothionic acid [3], while breakdown con- stituents of biodegradation include beta monocarboxylic acid, dicarboxylic acid, and diethyl thiomalate [4]. Although the current water treatment methods are less efficient in getting rid of pesticides and their degradation products, some recent developments incorporate zeolites among water purifiers as a means to removing cations and some organics $[5,6]$.

Faujasite $\mathrm{X}(\mathrm{NaX}$ or $\mathrm{X})$ and Faujasite $\mathrm{Y}(\mathrm{NaY}$ or $\mathrm{Y})$ zeolites can be effective alternatives for mopping up malathion from waters due to their abilities to abstract and catalyze degradation of organophosphates [7, 8]. Although zeolite X and $\mathrm{Y}$ have similar topographical structure, they differ in their pore diameter $(7.3 \AA$ for $\mathrm{X}$ and $7.4 \AA$ for $\mathrm{Y})$ and $\mathrm{Si} / \mathrm{Al}$ ratio (1.00-2.50 for $\mathrm{X}$ and more than 2.50 for $\mathrm{Y})$ making their chemistry also somewhat different [9]. Ref. [8], reported that zeolites degrade malathion faster though the kinetics of such zeolitic action, the nature of reaction products, and the toxicity or otherwise of the degradation products have not been documented. The current study, therefore, investigated the possible effects when low $\mathrm{Si} / \mathrm{Al}(\mathrm{X})$ compared to a high $\mathrm{Si} / \mathrm{Al}(\mathrm{Y})$ zeolites were used to decontami- 
nate fresh water off malathion.

\section{Materials and Methods}

\subsection{Chemicals}

The n-hexane, dichloromethane and diethyl ether solvents used were supplied by Kobian Ltd, Nairobi, Kenya, and were all of Analytical Reagent (AR) grade. Analytical grade anhydrous $\mathrm{Na}_{2} \mathrm{SO}_{4}$, and $\mathrm{NaCl}$ both $99 \%$ pure, Purified Reagent (PR) grade Florisil, activated charcoal PR grade and Whatman No. 1 filter papers were also obtained from Kobian Ltd. Analytical standard malathion and both zeolite $\mathrm{X}$ and zeolite $\mathrm{Y}$ were obtained from Sigma-Aldrich Inc, St. Louis, USA.

\subsection{Water Sampling}

Forty (40) litres of Lake Victoria water was collected from Asembo Bay $\left(0^{\circ} 10^{\prime} \mathrm{S}, 34^{\circ} 25^{\prime} \mathrm{E}\right), 100 \mathrm{~m}$ offshore and about 30 $\mathrm{cm}$ from the surface. The initial $\mathrm{pH}$ of the water was measured using an Everscale pH-03(Shanghai, China) and thereafter the water was filtered into a pre-cleaned $20 \mathrm{~L}$ plastic container using Whatman No 1 filter paper to remove any suspended particles. The lake water used was first stored in the dark at room temperature for about two weeks before use.

\subsection{Degradation Experiments}

All the set-ups were laboratory based in a water bath at 27 $\pm 1{ }^{\circ} \mathrm{C}$. In the setup, one litre of water sample in a pre-cleaned $2 \mathrm{~L}$ glass jar was spiked with malathion pre-dissolved in $2 \mathrm{mls}$ of acetone so as to make 5, 10 and 20 ppm malathion concentrations and then $1.0 \mathrm{~g}$ of activated zeolite $\mathrm{X}$ added in each case. Another similar set of malathion solutions but without any zeolites was also separately prepared as a control for this set up. A blank was prepared by taking $1 \mathrm{~L}$ of water sample into a $2 \mathrm{~L}$ glass jar and adding 1.0 g activated zeolite $X$. After every 1, 2, 4, 6, 12, 24, 48, 96, 192, 384 and 768 hours, $40 \mathrm{~mL}$ from each set up was transferred to a clean amber bottle and kept at $4{ }^{\circ} \mathrm{C}$ before analysis. The same procedure was repeated for zeolite $\mathrm{Y}$ incorporated samples. At the end of the study duration, the solid zeolite cakes of both the zeolites $\mathrm{X}$ and $\mathrm{Y}$ treatments and the blank set-ups were dried by pressing the cake in between Whatman No. 1 filter papers. The dried cakes were then considered ready for X-ray diffraction (XRD) and Fourier Transform Infra Red (FT-IR) characterization.

\subsection{Extraction and Clean $U p$}

The $40 \mathrm{ml}$ of the extracted samples were transferred into a $100 \mathrm{ml}$ separating funnel and 2 grams of $\mathrm{NaCl}(\mathrm{s})$ was added to each sample to facilitate extraction of the malathion. 20 $\mathrm{mL}$ of dichloromethane was then added to the mixture and the mixture shaken for about 5 minutes, with periodical venting to release pressure [10]. The mixture was allowed to stand for ca. 10 minutes to afford a clear separation between the aqueous and the organic layers. The aqueous layer was then drained into a second separation funnel and the organic layer transferred into a clean $100 \mathrm{ml}$ Erlenmeyer flask. The aqueous phase was then twice extracted with fresh solvents. The extracts were first combined then dehydrated by $10 \mathrm{~g}$ anhydrous $\mathrm{Na}_{2} \mathrm{SO}_{4}$. To remove the clumped $\mathrm{Na}_{2} \mathrm{SO}_{4}$ crystals from the extracts, vacuum filtration was performed. The dried sample was then concentrated by rotary evaporation at $40{ }^{\circ} \mathrm{C}$ to a $10 \mathrm{~mL}$ final volume.

Then cleaning up in an n-hexane washed glass column (2 $\mathrm{cm}$ i.d) packed with $20 \mathrm{~g}$ Florisil followed. Earlier, $2 \mathrm{~g}$ of the anhydrous $\mathrm{Na}_{2} \mathrm{SO}_{4}$ and $1 \mathrm{~g}$ of activated charcoal were also added at the top of the column to remove any pigmentation. The elution was sequentially done with $50 \mathrm{ml}$ of n-hexane, followed by $200 \mathrm{ml}$ of $6 \%$ diethyl ether in n-hexane, $200 \mathrm{ml}$ of $15 \%$ diethyl ether in $\mathrm{n}$-hexane and finally by $200 \mathrm{ml}$ of $50 \%$ diethyl ether in n-hexane and the fractions collected (www.caslab.com/EPA-Method-3620c, accessed on March 18th 2012). The third fraction was concentrated to dryness in a rotary evaporator in a water bath temperature at $40{ }^{\circ} \mathrm{C}$. Three milliliters of HPLC grade n-hexane was used to reconstitute the analyte before analysis and quantification.

\subsection{Analysis}

Varian Chrompack CP-3800 Gas chromatograph (GC) acquired from Palo Alto, CA, USA with Nitrogen-Phosphorus Detector (NPD) was used for the analysis. The capillary column was a DB-210 of length $30 \mathrm{~m}$, id 0.25 $\mathrm{mm}$ and $0.25 \mu \mathrm{m}$ film. The carrier and make up gas was nitrogen with a $2 \mathrm{ml} / \mathrm{min}$ and $30 \mathrm{ml} / \mathrm{min}$ flow rates respectively. Hydrogen at $8 \mathrm{ml} / \mathrm{min}$ and air at $80 \mathrm{ml} / \mathrm{min}$ were employed in a splitless mode for the detector. $2.0 \mu \mathrm{L}$ of the sample was injected at a temperature of $270{ }^{\circ} \mathrm{C}$. The oven temperature was kept at $120^{\circ} \mathrm{C}$ with a hold time of 1 minute, then from $120{ }^{\circ} \mathrm{C}$ to $205{ }^{\circ} \mathrm{C}$ at a rate of $25{ }^{\circ} \mathrm{C} / \mathrm{min}$ with a hold time of 1 minute and finally from $205{ }^{\circ} \mathrm{C}$ to $250{ }^{\circ} \mathrm{C}$ at a rate of $1{ }^{\circ} \mathrm{C} / \mathrm{min}$ with a hold time of 1 minute. The detector was maintained at $300{ }^{\circ} \mathrm{C}$. The detection limit calculated as the standard deviation of triplicate analyses with a 95\% confidence level was $0.01 \mathrm{ppm}$ for malathion. The recovery for malathion was $73.6 \pm 4.7 \%$. The malathion peak was characterized by comparing the retention times and area count with those of the external standard while the degradation products were identified and confirmed using GC-Mass spectroscopy (GC-MS).

The Gas Chromatography -Mass spectrophotometer (GC-MS) (Agilent 6890 GC and 5975 MS, EI) from Agilent technologies, Santa Clara CA, USA was used for the analysis. The capillary column was a VF5 ms of length $30 \mathrm{~m}$, i.d $320 \mu \mathrm{m}$ and $0.25 \mu \mathrm{m}$ film. The carrier gas was helium with flow rate $1.2 \mathrm{ml} / \mathrm{min}$ in splitless mode with sample injection volume of $2 \mu \mathrm{l}$. The injector temperature was maintained at $250{ }^{\circ} \mathrm{C}$. The oven temp was programmed as: $60{ }^{\circ} \mathrm{C}$, hold time $0 \mathrm{~min}$ then to $165^{\circ} \mathrm{C}$ at $15^{\circ} \mathrm{C}$ hold time $0 \mathrm{~min}$ then to $280{ }^{\circ} \mathrm{C}$ at $2{ }^{\circ} \mathrm{C}$ hold time $1 \mathrm{~min}$. MS detector temperature was $280{ }^{\circ} \mathrm{C}$, that of Quadrouple was $150{ }^{\circ} \mathrm{C}$ and source temperature of $230{ }^{\circ} \mathrm{C}$. The GC-MS was operated in a SIM/SCAN 
Mode and the following were the SIM ions: (Target) 127, (Q1)173, (Q2)158.

The X-ray diffraction (XRD) data was collected at room temperature on a Scintag XDS 2000 powder diffractometer using $\mathrm{Cu} \mathrm{k} \alpha$ radiation of $\lambda=1.5418 \AA$ with a solid state detector. The instrument settings were $40 \mathrm{KV}, 30 \mathrm{~mA}$, step size of $0.02^{\circ}(2 \theta)$ and a scan rate of $2 \theta / \mathrm{min}$ for $5^{\circ} \leq 2 \theta \leq 50^{\circ}$. The FT-IR measurements were done on the Bruker Equinox 55 spectrometer from Madison, WI, USA with a nominal resolution of $2 \mathrm{~cm}^{-1}$. The spectrometer was purged with nitrogen gas for 30 minutes before and after pellet insertion, after which the spectrum was recorded over the $4000-400$ $\mathrm{cm}^{-1}$ range. A total of 128 scans were collected for each sample spectrum.

\section{Results and Discussions}

\subsection{Effects of Zeolites on Degradation Rate of Malathion}

Lower malathion concentrations of 5 and $10 \mathrm{ppm}$ were first investigated but the pesticide residual amounts in water with time especially after exposure to zeolites were minimal and could not enable time dependent study of this nature to be performed. Consequently, only the results for $20 \mathrm{ppm}$ malathion concentration are reported herein. A gain, the data reported here are corrected for loses occasioned by volatilization, evaporation and adherence to container walls.

Over the period of study, the $\mathrm{pH}$ of water before the treatments with zeolite was $7.8 \pm 0.5$, while that after zeolite $\mathrm{X}$ treatments was $8.1 \pm 0.6$ and after zeolite $\mathrm{Y}$ treatments was $8.0 \pm 0.5$. On average, the changes in the $\mathrm{pH}$ of water both before and after zeolite addition and in the course of reaction were statistically insignificant. Significantly, differences in malathion dissipation existed in the waters treated with the zeolites compared to those in untreated waters (Table 1). The initial dissipation of malathion in water without zeolite could be attributed to photolysis and the transformation of malathion to its degradation products which are majorly acids. Ref. [11] had also noted this phenomenon where the malathion concentration continued dropping as the transformation proceeded. In the long term, the rate of degradation continued to significantly slow down and was almost stagnated by the $20^{\text {th }}$ hour of study.

In Table 1, the lower $\mathrm{Si} / \mathrm{Al}$ zeolite $\mathrm{X}$ showed slightly higher percentage removal of malathion with time as compared to the higher $\mathrm{Si} / \mathrm{Al}$ zeolite Y. This increased dissipation rate is attributable to the catalytic action and/or adsorption of the zeolites.

A first-order kinetics was obtained for the dissipation of the malathion in all the three media of water alone, when exposed to $\mathrm{Y}$ and when exposed to $\mathrm{X}$ with half-lives of 8.76 , 6.65 , and 4.44 hours, respectively. Ref. [12], reported a half-life of 2 days at $28{ }^{\circ} \mathrm{C}$ and a $\mathrm{pH}$ of 8.2 , while ref. [4] reported a half-life of 2 days but under unspecified conditions thus underscores that the differences in the half-lives could be attributed to the different climatic conditions since the literature data cited above were acquired in the temperate regions while the current study was in the tropics [13]. The reduction in half-life in the presence of zeolites is in agreement with past studies which indicated that zeolites are capable of enhancing the degradation of organophosphates [7]. The enhanced degradation of malathion by zeolites is attributable to zeolitic catalysis since the zeolites are imbued with higher amounts of both exchangeable cations and cavity dielectric charge which would contribute in the reaping a part of the molecule [9]. Since Faujasite X has more exchangeable cations in its cavities than Faujasite Y [14] its reaction is therefore expected to be faster than the $\mathrm{Y}$ type as observed in this study.

Table 1. Amount of malathion residue in water alone, water treated with zeolite $X$ and water treated with zeolite $Y$. Where n.d = means non-detectable concentration level. All the concentrations are expressed as $($ ppm \pm S.D) where $n=3$

\begin{tabular}{llll}
\hline $\begin{array}{l}\text { Time } \\
\text { (hrs) }\end{array}$ & $\begin{array}{l}\text { Malathion } \\
\text { in Water alone } \\
\text { (ppm) }\end{array}$ & $\begin{array}{l}\text { Malathion } \\
\text { in X + Water } \\
\text { treatment }(\mathbf{p p m})\end{array}$ & $\begin{array}{l}\text { Malathion } \\
\text { in Y + Water } \\
\text { treatment (ppm) }\end{array}$ \\
\hline 1 & $5.18 \pm 0.04$ & $2.78 \pm 0.08$ & $5.13 \pm 0.04$ \\
2 & $4.21 \pm 0.05$ & $2.13 \pm 0.10$ & $3.08 \pm 0.05$ \\
4 & $2.93 \pm 0.11$ & $1.42 \pm 0.09$ & $1.74 \pm 0.11$ \\
6 & $1.99 \pm 0.06$ & $0.95 \pm 0.11$ & $1.36 \pm 0.06$ \\
12 & $1.18 \pm 0.03$ & $0.56 \pm 0.11$ & $0.95 \pm 0.03$ \\
24 & $0.58 \pm 0.01$ & $0.27 \pm 0.03$ & $0.38 \pm 0.01$ \\
48 & $0.24 \pm 0.02$ & n.d & n.d \\
96 & $0.10 \pm 0.02$ & n.d & n.d \\
\hline
\end{tabular}

\subsection{Degradation Products of Malathion in Fresh Water}

Fig. 1 shows the degradation trend of the malathion and the accumulation of its degradation products in fresh water. Under ordinary aquatic conditions, the hydrolysis breakdown sequence for the malathion (Mal.) follows both parallel and consecutive reaction mechanism resulting in malathion monocarboxylic acid (MMCA), malathion dicarboxylic acid (MDCA), Fumaric acid (FA), diethyl mercaptosuccinate (0,0- Dimethyl S- [1,2- bis (ethoxy- carbonyl) ethyl ] dithiophosphate ) (DEMS), O, O- dimethylphosphorothiolate ( DEPT), and, O, O- dimethylphosphorodithionate (DMPDT) as degradation products. In some cases, a more toxic malaoxon is also a product [15]. Here, the only degradation products of malathion found in the fresh water (Fig. 1) were the malathion monocarboxylic (MMCA) and malathion dicarboxylic (MDCA) acids. This is in agreement with the reports by ref. [16] who similarly obtained the same products.

Typical of mechanisms for consecutive reactions, the accumulation trend of the products as shown in Fig. 1 indicates an equal production rates for both the MMCA and MDCA up to the $50^{\text {th }}$ hour thereafter the MMCA concentration peaked over that of MDCA. The $50^{\text {th }} \mathrm{hr}$ coincided with the point when the degradation rate of malathion is, to the best approximation, zero. Such a trend where the daughter 
(MDCA) becomes more prominent after the depletion of the reactants (Mal.) is consistent with a consecutive reaction [17].

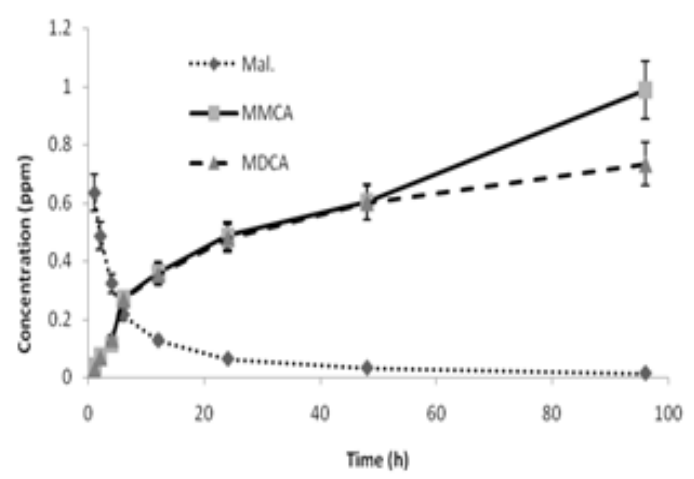

Fig. 1. Degradation trend of malathion and accumulation its degradation products in water.

However in the presence of the zeolites $\mathrm{X}$ and $\mathrm{Y}$, in addition to the MMCA and MDCA that were obtained in fresh water, Dimethyldithiophosphonate (DMDTP) was detected. The trend of degradation of the malathion in the presence of zeolite $\mathrm{Y}$ is presented in Fig. 2.

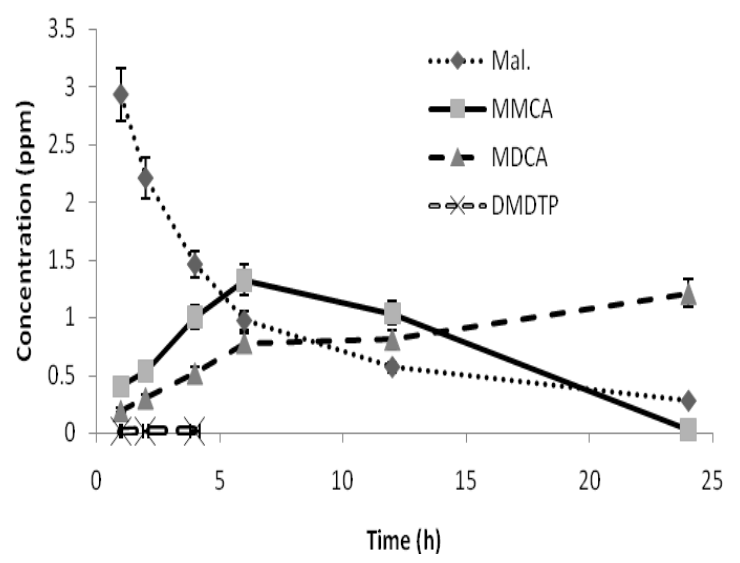

Fig. 2. Distribution of malathion and its degradation products in the presence of zeolite $Y$.

Here, the DMDTP was in minimal amounts and could only be detected up to the $5^{\text {th }}$ hour. In addition, the zeolite $\mathrm{Y}$ afforded an increasing concentration of MMCA up to the $6^{\text {th }}$ hour followed by a gradual decrease till the end of study period (Fig. 2).

Somewhat similar degradation pattern to that for $\mathrm{Y}$ was also observed for $\mathrm{X}$ treatment (Fig. 3). Unlike in water alone, the quantity of the MMCA product increased up to the $6^{\text {th }}$ hour, there after it decreased to maintain a constant amount from the $15^{\text {th }}$ hour to the end of the study duration. Such an increase followed by a decrease in the concentration of MMCA is expected since it is a sequential hydrolysis of malathion that leads to formation of MMCA after which the MMCA degrades further to MDCA. Meaning that the increase from the start to the sixth hour then a decrease in the concentration of MMCA is attributable to the sorption-desorption by the zeolites [7] followed by the sequential formation of the MDCA.

A gain, as opposed to the type of products in the water alone, both Zeolite $\mathrm{X}$ and $\mathrm{Y}$ treatments afforded the DMDTP as an additional product however the amounts were minimal (Fig. 2, and Fig. 3). Conversely, the failure to detect DMDTP in water alone could be attributed to the paucity of dissolved water-bound cations that could stabilize the DMDTP as possibly happened for Zeolite-Na-DMDTP. The $\mathrm{Na}^{+}$ions stabilizing the DMDTP could have been availed from the $\mathrm{NaX}$ and $\mathrm{NaY}$ zeolites used.

The degradation products (MMCA, MDCA and DMDTP) realized for Y (Fig. 2) and for X (Fig. 3) from the zeolite treatments had much lower toxicity levels than malathion itself and other degradation products of malathion in an aqueous medium [18]. It is worthy to note that malaoxon; a common and more toxic product of malathion degradation in most aqueous environments [3], was not detected in this work.

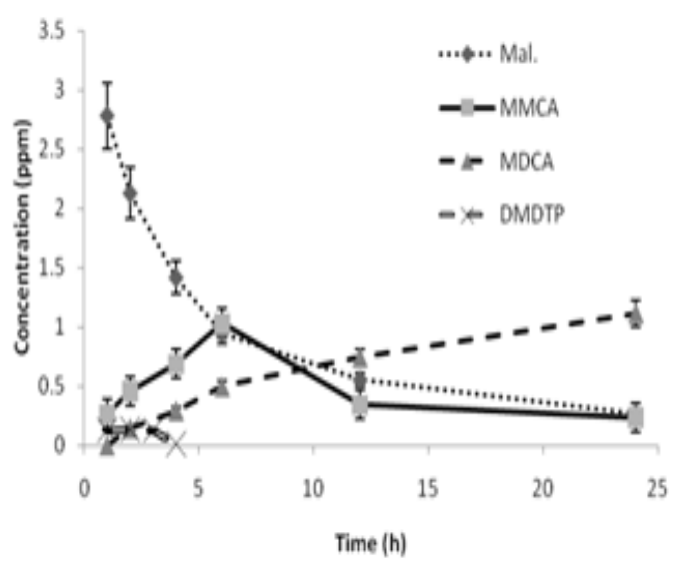

Fig. 3. Distribution of malathion and its degradation products in presence of zeolite $X$.

Statistically, there were several statistically significant differences between the effects of zeolites $\mathrm{X}$ and zeolite $\mathrm{Y}$ on the dissipation behaviour of malathion and its products (Table 2). Similarly, there were also significant changes in the degradation rates with time and the degradation patterns were also statistically different save for that of DMDTP in which the interaction was not significant.

Table 2 indicates that water treated with the zeolites made malathion dissipate faster than in the untreated. In comparison, zeolite $\mathrm{X}$ is more efficient in enhancing the degradation of malathion than zeolite Y. Such a difference is expected since the number of exchangeable univalent cations vary from about 10-12 per cage for zeolite $X$ to as low as 6 for high silica zeolite $\mathrm{Y}$ [14]. Consequently, as compared to zeolite $\mathrm{Y}$, zeolite $\mathrm{X}$ acquires a larger framework electronic charge for more effective catalysis and adsorption resulting to a faster dissipation rate for the pesticide than in zeolite Y. This observation concurs with previous studies which reported that zeolites $\mathrm{X}$ had higher degradation efficiency when compared to $\mathrm{Y}$ [19]. In effect, lower Si/Al zeolites would favour faster rates of malathion degradation. 
Table 2. Variation of malathion and its degradation products with zeolite type and reaction time. Where NS =not significant.

\begin{tabular}{|c|c|c|c|c|c|c|c|c|}
\hline \multirow{2}{*}{ Products } & \multirow{2}{*}{ Treatments } & \multicolumn{6}{|c|}{ Time(hr) } & \multirow{2}{*}{ Mean for zeolite } \\
\hline & & 1 & 2 & 4 & 6 & 12 & 24 & \\
\hline \multirow{6}{*}{$\begin{array}{l}\text { Mal. } \\
\text { (ppm) }\end{array}$} & Zeolite X & 2.784 & 2.130 & 1.418 & 0.949 & 0.558 & 0.271 & 1.352 \\
\hline & Zeolite Y & 2.932 & 2.207 & 1.458 & 0.970 & 0.567 & 0.274 & 1.401 \\
\hline & Mean time & 2.858 & 2.169 & 1.438 & 0.960 & 0.563 & 0.272 & \\
\hline & $\mathrm{CV} \%$ & & & & 2.570 & & & \\
\hline & LSD $p \leq 0.05$ & & & & 0.052 & & & 0.149 \\
\hline & Interaction & & & & 0.074 & & & \\
\hline \multirow{6}{*}{$\begin{array}{l}\text { MMCA } \\
(\mathrm{ppm})\end{array}$} & Zeolite X & 0.270 & 0.459 & 0.691 & 1.030 & 0.346 & 0.238 & 0.506 \\
\hline & Zeolite Y & 0.402 & 0.532 & 1.003 & 1.325 & 1.037 & 0.021 & 0.720 \\
\hline & Mean time & 0.336 & 0.496 & 0.847 & 1.178 & 0.691 & 0.130 & \\
\hline & $\mathrm{CV} \%$ & & & & 6.790 & & & \\
\hline & LSD $p \leq 0.05$ & & & & 0.062 & & & 0.176 \\
\hline & Interaction & & & & 0.087 & & & \\
\hline \multirow{6}{*}{$\begin{array}{l}\text { MDCA } \\
(\mathrm{ppm})\end{array}$} & Zeolite X & 0.244 & 0.267 & 0.496 & 0.741 & 1.113 & 1.454 & 0.719 \\
\hline & Zeolite Y & 0.193 & 0.303 & 0.518 & 0.781 & 0.810 & 1.208 & 0.635 \\
\hline & Mean time & 0.218 & 0.285 & 0.507 & 0.761 & 0.962 & 1.331 & \\
\hline & CV\% & & & & 11.200 & & & \\
\hline & LSD $p \leq 0.05$ & & & & 0.112 & & & 0.322 \\
\hline & Interaction & & & & 0.159 & & & \\
\hline \multirow{6}{*}{$\begin{array}{l}\text { DMDTP } \\
(\mathrm{ppm})\end{array}$} & Zeolite X & 0.134 & 0.141 & 0.132 & 0.034 & 0.000 & 0.000 & 0.073 \\
\hline & Zeolite Y & 0.013 & 0.014 & 0.015 & 0.000 & 0.000 & 0.000 & 0.007 \\
\hline & Mean time & 0.074 & 0.077 & 0.073 & 0.017 & 0.000 & 0.000 & \\
\hline & $\mathrm{CV} \%$ & & & & 4.110 & & & \\
\hline & LSD $p \leq 0.05$ & & & & 0.045 & & & 0.128 \\
\hline & Interaction & & & & NS & & & \\
\hline
\end{tabular}

To monitor framework changes within the zeolites such as any migrations by the exchangeable cations that could corroborate a cation-aided catalysis, XRD analysis was performed. Typical of XRD diffractograms for Faujasite framework, intensity changes for the $9.9^{\circ}(2 \theta)$ and $11.6^{\circ}(2 \theta)$ diffractograms depict cationic migrations [20]. In this set-up, such a migration would signify the participation of the framework $\mathrm{Na}^{+}$ions in the degradation mechanism. After normalising the peak intensities for the two graphs (X0 unreacted $\mathrm{X}$, and X20 - exposed to $20 \mathrm{ppm}$ malathion) and setting the relative intensity of the strongest peak to 1.00 arbitrary units (a.u.) (ca. $6.0^{\circ}(2 \theta)$ ), the corresponding relative inteinsities for the other peaks were similarly calculated and are as shown in Fig. 4.

From Fig. 4, the exposure of zeolite $X$ to malathion had significant effect on the relative intensities of the diffracto- grams at ca. $9.9^{\circ}(2 \theta)$ changing from ca. 0.63 to 0.27 a.u. Simultaniously, the ralative intensity of that at $11.6^{\circ}(2 \theta)$ minimaly increased from ca. 0.20 to 0.22 . Similar exposure of the Zeolite $\mathrm{Y}$ to malathion resulted in a similar though minimal effect on the relative intensities of the diffractograms at $9.9^{\circ}(2 \theta)$ from 0.23 to 0.21 , while that at $11.6^{\circ}(2 \theta)$ the intensity substantially increased from 0.16 to 0.22 (Fig. not shown). Such intensity changes corroborate cationic migrations from one site to another within the framework [20]. The changes depicted in Fig. 4 are therefore consistent with the involvement of $\mathrm{Na}^{+}$ions in the mechanism of this degradation. Due to the observed ralatively high changes in the diffractograms intensities for $\mathrm{X}$ treatments, the XRD analysis therefore implies zeolite $\mathrm{X}$ has better catalytic and/or adsorption properties than Y. In addition, the difference in the amount of exchangeable $\mathrm{Na}^{+}$ion concentration 
between the $\mathrm{X}$ and the $\mathrm{Y}$ treatments explains the observed differences in the DMDTP concentrations between X (Fig.2) and Y (Fig. 3) values. Therefore, it is understandable when $\mathrm{X}$ treatments had a higher concentration of the DMDTP compared to Y treatments.

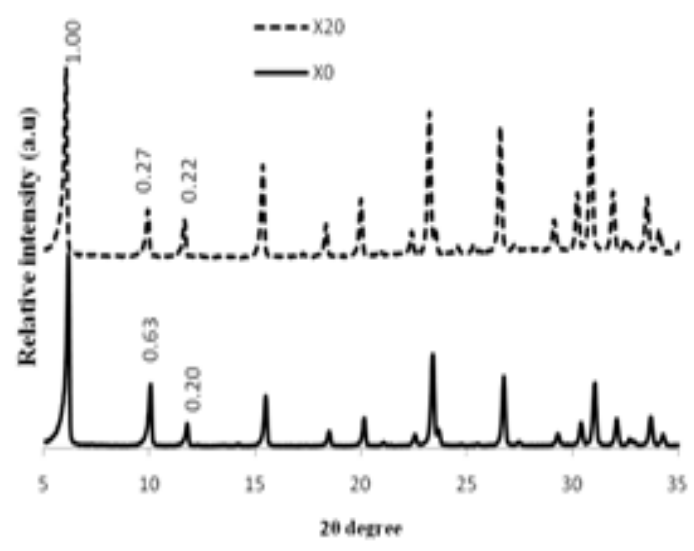

Fig. 4. $X R D$ spectra for zeolite $X$ in malathion. Where $X 0=$ zeolite $X$ with 0 ppm malathion, $X 20=$ zeolite $X$ with 20 ppm Malathion.

To ascertain whether some amounts of the malathion and its degradation products were adsorbed in the zeolite matrix, a FT-IR characterization was performed. In IR, any changes in mass of the vibrating components, either through attachments or dissociations would result in a blue or red shift, respectively [20].

The Single-Four-Ring (S4R) which in a free zeolite X vibrates at ca. $764 \mathrm{~cm}^{-1}$ was shifted to ca. $742 \mathrm{~cm}^{-1}$ up on exposure to the malathion. A similar, though moderate shifting from ca. $770 \mathrm{~cm}^{-1}$ to $755 \mathrm{~cm}^{-1}$ was observed for the zeolite Y. A part from the above listed vibrational band shiftings, no any other changes were noted for the remaining finger-print bands. Assuming other factors are constant, such shifting imply an increase in the mass of vibrating framework which is consistent with the adsorption of some malathion or its degradation products on to the zeolite matrix. The attachment implies that apart from catalytic degradation of the pesticide, adsorption was also a major player in the decrease in concentration of the malathion in zeolite treatments. However, this work could not quantify how much of the malathion or its degradation products were adsorbed.

\section{Concluding Remarks}

The lower malathion concentrations of 5 and 10 ppm were totally adsorbed by both zeolite $\mathrm{X}$ and $\mathrm{Y}$. Thus for zeolites to be used in drinking water purification, knowing the adsorption capacity and the $\mathrm{Si} / \mathrm{Al}$ ratio of the individual zeolite is important. Faujasite zeolites were found to enhance the degradation of malathion, at $20 \mathrm{ppm}$, in water with the $\mathrm{X}$ type being faster than the $\mathrm{Y}$ type. Both the adsorption and catalytic activities significantly contributed in the dissipation processes of the malathion. The amount of exchangea- ble $\mathrm{Na}^{+}$ions in the zeolite framework dictated the rate of and the nature of the product formed during the dissipation. Malathion degradation in fresh water and in the presence of zeolites produces the malathion monocarboxylic, malathion dicarboxylic acid and dimethyldithiophosphate as the degradation products. The more toxic maloxon was not produced during the malathion degradation when zeolite is used.

\section{Acknowledgements}

We are grateful to Mr. Iyoki of Chemical System Engineering Department, University of Tokyo, Japan for XRD and IR analysis and Mr. Bowa of Chemistry Department, Maseno University for his help with data analysis.

\section{References}

[1] NPIC, 2001. Malathion: Technical Fact Sheet. National Pesticide Information Center. Oregon State University, Corvallis, OR, USA.

[2] Ogutu-Ohwayo, R. Muggide, R. Batirwa, J.S. 2002. Technical guidelines for management of fisheries resources, biodiversity and environment of Victoria basin lakes. Technical document No.1. Jinja Fisheries Resource Research Institute, Uganda

[3] Newhart, K. 2006. Environmental fate of Malathion. Environmental monitoring branch, department of pesticide regulation. California Environmental Protection Agency. CA. USA.

[4] Neal, R. McCool, P. Younglove, T. 1993. Assessment of malathion and malaoxon concentration and persistence in water, sand, soil and plant matrices under controlled exposure conditions. California department of pesticide regulation. Environmental hazards assessment program. University of California, Riverside, CA. USA.

[5] Banerji, S.K. 1999. Environmental chemistry, 2nd Ed. Prentice-Hall of India, New Delhi, India.

[6] Kallo, D. 2001. Application of natural zeolites in water and wastewater treatment. Rev. in mineral. and geochem. 45(1): 519-550.

[7] Yang, S.W. Doetschman, D.C. Schulte, J.T. Sambur, J.B. Kanyi, C.W. Fox, J.D. Kowenje, C.O, Jones, B.R. Shema, N.D. 2006. Sodium X-Type faujasite zeolite decomposition of Dimethyl methylphosphonate(DMMP) to methylphosphonate. Nucleophilic zeolite reactions I. Microporous and mesoporous mater. 92, 56-60.

[8] Kanan, S.M. Kanan, M.C. Patterson, H.H. 2006. Silver nanoclusters doped in $\mathrm{X}$ and mordenite zeolites as heterogeneous catalysts for the decomposition of carbamate pesticides in solution. Res. Chem. Intermed. 32(9), 871-885.

[9] Satterfield, C.N. 1980. Heterogenous catalysis in practice. McGraw-Hill, New York. pp 301-308.

[10] Zweig, G. Devine, J.M. 1969. Determination of organophosphorus pesticide in water. Residue Rev. 26, 17-36.

[11] Zheng, Y. Hwang, H.M. 2006. Effects of temperature and 
microorganisms on Malathion transformation in river water. Bull. Environ. Contam. Toxicol. 76(4): 712-719.

[12] Wang, T.C. Hoffman, M.E. 1991. Degradation of organophosphorus pesticides in coastal water. J. Assoc. Off. Anal. Chem. 74, 883-886.

[13] Freed, V.H. Chiou, C.T. Schmedding, D.W. 1979. Degradation of selected pesticide in water and soil. J. Agric. Food Chem. 27(4): 706-708.

[14] Mortier, W.J. Costenoble, M.L. Uytterhoeven, J.B. 1973. Location of cations in synthetic zeolite X and Y, III. Potassium-alkylammonium Y zeolites. J. phy. Chem. 77(24): 2880-2885.

[15] Teeter, D. 1988. Malathion (AC 6, 601): Hydrolysis. American Cyanamid Company study: PD-M25-59. Cheminova report No.12FYF summary. Wayne, NJ, USA.
[16] Howard, P.H. 1991. Handbook of environmental fate and exposure data for organic.

[17] House, J. E. 1997. Principles of Chemical Kinetics, Wm. C. Brown Publishers. Chicago, USA, pp 40-45.

[18] Mehlhorn, H. Armstrong, P.E. 2001. Encyclopedic reference of parasitology: disease, treatment and therapy. 2nd edition. Springer-verlag, Berlin. pp 674-678.

[19] Kanyi, C.W. Doetschman, D.C. Schulte, J.T. Yan, K. Wilson, R.E. Jones, B.R. Kowenje, C. O. 2006. Linear, primary monoalkanes chemistry in $\mathrm{NaX}$ and $\mathrm{NaY}$ faujasite zeolite with and without $\mathrm{Na}$-treatment. Zeolite as nucleophilic reagents II. Microporous and Mesoporous Mater., 92, 292-299.

[20] Kowenje, C.O. Jones, B.R. Doetschman, D.C. Yang, S-W. Schulte, J. DeCoste, J. Kanyi, C. W. 2010. Effects of copper exchange levels on complexation of ammonia in $\mathrm{Cu}$ (II)-exchanged X zeolites. S. Afr. J. Chem., 63, 6-10 